Gowland Hopkins called 'waste products that function in ornament'-seem ever to be increasing in metabolic importance as growth factors, photolabile receptors, co-factors for the transfer of 'active formate' and so on ; and some of the most suggestive work is still being done on insects. Although best known in insects, the ommochromes and their relation to tryptophan metabolism are of general interest for the light they have thrown on gene action. The sclerotin of insect cuticle, formed by the quinone tanning of protein, constitutes a new type of natural polymer which still awaits biochemical analysis: and insects provide the ideal material for studying the biochemistry of morphogenesis.

The author recognizes physiology as a reputable dizcipline, but he does not allow himself to be diverted into physiological discussions, beyond the minimum necessary to link up his biochemical arguments. $\mathrm{He}$ always draws a clear distinction between what is surmised and what has been demonstrated. All this makes a book that is distinctive and stimulating in the sense that the reader feels a strong urge to go and fill the gaps in our knowledge. Almost every point made is documented by references to original work.

V. B. WiggLesWorTh

\section{EVOLUTION AND PHILOSOPHY}

The Ascent of Life

A Philosophical Study of the Theory of Evolution. By Prof. T. A. Goudge. Pp. 236. (London: George Allen and Unwin, Ltd., 1961.) 30s. net.

7 HIS book may be warmly recommended precisely

because it gives a sustained philosophical discussion of modern evolutionary theory. It is eminently readable and its moderate tone should ensure for it a place on the bookshelf of every professional evolutionist. This is not to say, however, that the arguments in the book are wholly convincing or without blemish. The philosophical approach is chiefly that of the neo-positivist or empiricist, and this approach has clearly limited the scope and value of the book. Prof. Goudge seems to consider that a philosophical explanation, while going beyond the empirical facts and assumptions, is somehow immanent in them but cannot be transcendent to them unless capable of empirical application. This point of view would again seem to narrow the value of the interpretations given. I am sure many people consider that the value of a philosophical explanation of a biological theory is precisely because it may go far beyond the theory into a wider realm of meaning which the theory may have for us in both our sentient and intellectual lives.

After an introduction and a second chapter, which is described as historical but does not give much actual history, Prof. Goudge begins the main chapters of the book. The evolutionary theory mainly considered is that of modern selection, and even here this explanation is practically limited to evolution in the light of population genetics. A certain courage is here manifested by the author because population genetics is new, highly abstracted, speculative, and its models are greatly simplified versions of the real picture. It may be fashionable to consider that evolution occurs through 'populations', but it is a serious mistake to give a philosophical account of evolution which implies that evolution occurs only by this method. There just is no evolutionary or genetical reason why a single individual (or a single pair) of organisms should not start, or have started, a new evolutionary line. This is a point which is important in considering the evolution of man, and it is missed completely by Prof. Goudge.

Other legitimate biological theories which are often misunderstood and have never been philosophically refuted, such as vitalism, finality or neo-Lamarckism are, indeed, mentioned but are unfortunately given scant treatment. On the question of finality alone the fundamental point, that without the assumption of finality many scientific statements could scarcely even be made, is ignored. It is a pity also that the basic assumptions of the theory of evolution are not given any philosophical treatment. Nevertheless, there is a wealth of ideas and suggestions in this book which should enlarge the vista of the evolutionary biologist.

P. G. Fothergill

\section{HUMAN GENETICS}

\section{Recent Advances in Human Genetics}

Edited by Prof. L. S. Penrose, with the assistance of Helen Lang Brown. Pp. vii + 194. (London: J. and A. Churchill, Ltd., 1961.) 27s. 6d. net.

U UMAN genetics is now a branch of biology with its own methods. This is due largely to Penrose on the genetical side, and Tjio and Levan on the cytological. This small book is not a text, but consists of eight chapters by Penrose and six colleagues. In the first chapter Penrose summarizes recent work. on human mutation-rates and their dependence on age. $\mathrm{He}$ is sceptical of the high rates (median 28 mutations per chromosome per generation) estimated for autosomal recessive defects, as compared with a median value of 6 for dominants. He believes that they often are or have been advantageous to hetero. zygotes. The data on ages of parents of mutants are equally interesting, and make it clear that mutation at different loci must be due to wholly different processes. Harnden and Miller deal with chromosomal abnormalities, and some sexual abnormalities in chromosomally normal people. The most striking item in Penrose's chapter on foetal genetics is perhaps the map on p. 71 showing the distribution of anencephaly in Europe, with one peak in Ireland and western Britain, and another around Naples.

Gerald's article on the abnormal hæmoglobins is a useful snapshot of a very rapidly developing subject, and contains some 'stop-press news' which very much interested me. The subject will probably remain a little confused until a new technique is devised which will be as quick as electrophoresis, and which can distinguish between some chemically different variants that are not electrically separable. Holt deals with the ridge patterns of fingers and palms, which are among the most accessible of human characters, and, in view of the correlations exceeding 0.95 between monozygotic twins, must be mainly determined genetically. The last two chapters are largely statistical. Renwick describes the search for human linkage, and its estimation, while Smith deals mainly with other statistical problems, including his own remarkably efficient iterative method.

To a reader who had been cut off from reading for as short a time as two years, the chapters on chromosomal abnormalities and sex determination would be the most striking. Two years hence we should know a great deal more on these matters. But the whole book is very good. It is not free from errors, for 